Published as: Fatima Hashmi and Joshua M. Pearce, "Viability of Small-Scale Arsenic-Contaminated Water Purification Technologies for Sustainable Development in Pakistan", Sustainable Development, 19(4), pp. 223-234, 2011. http://dx.doi.org/10.1002/sd.414

\title{
Viability of Small-Scale Arsenic-Contaminated Water Purification Technologies for Sustainable Development in Pakistan
}

\author{
Fatima Hashmi and Joshua M. Pearce
}

Keywords: water purification, arsenic, Pakistan, appropriate technology, small scale technology

\begin{abstract}
Drinking arsenic-contaminated water leads to a series of health problems that has limited development for the largely poor rural people of Pakistan who are unable to afford bottled water, centralized treatment plants, or expensive water filter systems. This paper reviews the available appropriate technologies for the removal of arsenic in drinking water to assist in just sustainable development in Pakistan. Several technologies were found to be both technically- and economicallyviable and support the large-scale deployment of these small-scale, appropriate technologies. The economic viability determined in this study was based on both first costs and operating costs. The cost of implementing such technologies for an individual Pakistani family is made acceptable with the use of local materials, which the family may already own. For example, systems using sand and iron nails in the filters, and which are placed in plastic buckets that are already in common use in the villages, drive down the overall costs of the technology and put it in the reach of even the most destitute. This study found that complications from the variability of local supplies result in the need to identify the locally most appropriate solution from both a technical and economic standpoint. This review article should be helpful for any practitioner in determining the locally optimal solution for the removal of arsenic from drinking water in Pakistan.
\end{abstract}

\section{Introduction}

Pakistan is undergoing incredibly rapid development. It ranks in the top four of the "next generation of emerging economies" set to have significant impacts on the world economy (Grant Thornton International, 2007). Despite this rapid development and a relatively enormous new wealth generation, the majority of Pakistan's population remains in poverty, earning less than one U.S. dollar a day, with an average per capita income of US\$720 (World Bank, 2006). The current need for just sustainable development ${ }^{1}$ is more necessary in Pakistan than ever before. A major bottleneck in this development is the contamination of water supplies with arsenic (Ahmad, et al., 2004; Nickson, et al., 2005; Pakistan Council of Research in Water Resources, 2007a; Sutila, 2006; Ul-

1 Sustainable development can be defined as development that meets the needs and aspirations of the present without compromising the ability of future generations to meet their own needs (WCED, 1987). Particularly in this case, where the wealth disparity is so stark, a "just sustainable development" provides a clearer path toward progress (Agyeman, et al., 2003). Just sustainable development ensures a better quality of life for all, now and into the future, in a just and equitable manner, whilst living within the limits of supporting ecosystems. Just sustainable development applied to Pakistan prioritizes justice and equity, while maintaining the importance of the environment and the global life support system (Jacobs, 1999). 
Published as: Fatima Hashmi and Joshua M. Pearce, "Viability of Small-Scale Arsenic-Contaminated Water Purification Technologies for Sustainable Development in Pakistan", Sustainable Development, 19(4), pp. 223-234, 2011. http://dx.doi.org/10.1002/sd.414

Haque, et al., 2007). Arsenic-contaminated water has a disproportionate impact on the poor, who are the most vulnerable because they cannot afford centralized water purification or bottled water and often lack access to public health care facilities to treat arsenic-related diseases. The drinking of arsenic-contaminated water over long periods of time results in a myriad of health problems that seriously impair quality of life. Arsenicosis, the effects of arsenic poisoning (WHO, 2001), includes an increased risk of lung, skin, bladder and kidney cancer as well as certain skin diseases such as hyperkeratosis. Cardiovascular and nervous system dysfunctions, ultimately leading to death, are also known to occur due to arsenic consumption (Gomez-Caminero et al, 2001).

Most of the poor in developing countries rely on surface water for drinking, which is at a high risk of biological contamination. In order to reduce the risk of illness due to biological contaminants, previous Pakistani governments encouraged citizens to utilize groundwater (e.g. from wells) as it was free of such biological contamination. This had the unintended consequence of exposing citizens to high concentrations of arsenic in some areas where arsenic is a naturallyoccurring element in rocks and soil, and seeps into the groundwater. The natural sources of arsenic found in groundwater have been attributed to oxidation of arsenic-bearing sulfides, desorption of arsenic from hydro-oxides such as iron, aluminum and manganese oxides; reductive dissolution of arsenic-bearing iron hydro-oxides, release of arsenic from geothermal water, and evaporative concentration, as well as leaching of arsenic from sulfides by carbonates (Bennett and Dudas, 2003; Kim et al., 2000). In addition, arsenic contamination can be due to industrial (e.g. coal burning (Liu, et al., 2002)) and other anthropogenic activities, such as unconfined sewage (Nickson, et al, 2005), which can reduce hydrous ferric oxide to release arsenic into groundwater. In some regions of Pakistan, extremely high arsenic concentration was positively correlated with the concentration of iron, suggesting reductive dissolution of oxyhydroxides of iron (Ul-Haque, et al., 2007). In addition, extensive application of phosphate fertilizers triggers arsenic release from sediments and increases contamination concentrations further (Campos, 2002; Davenport and Peryea, 1991). Fortunately, the application rates of fertilizer, particularly of phosphate, are low in Pakistan (FAO, 2004). In Pakistan, the poor rural populations generally have their own wells and do not rely on a centralized water distribution system that may purify the water; hence they are the hardest hit by arseniccontaminated water.

In the past, arsenic contamination has been dealt with by large projects targeting the entire country. For example, the World Bank invested US\$32.4 million of IDA interest-free credit to address arsenic contamination in Bangladesh. These funds went primarily for testing, health surveys and provisions to provide clean water in contaminated areas. The belief at that time was that "there are, at present, few (if any) low-tech affordable solutions for the treatment of arsenic in non-piped water systems.” (Khouri and Chowdhury, 1999 p.96). In the last several years, there has been significant progress on the use of "low-tech" solutions to arsenic-contaminated water. As those in most need of sustainable development in Pakistan do not have access to improved water sources, appropriate technologies are needed to remove arsenic from the water. Appropriate technologies must be practical, they must be affordable to the poor and be able to be easily and economically constructed from readily-available materials by local craftspeople. Rather than focus on large-scale solutions to solve a regional problem with a high-capital project, this study focuses on the viability of household-scale technologies for arsenic removal in the low-income rural areas and villages throughout Pakistan that could be self-funded by families. This study provides a taxonomy and a 
Published as: Fatima Hashmi and Joshua M. Pearce, "Viability of Small-Scale Arsenic-Contaminated Water Purification Technologies for Sustainable Development in Pakistan", Sustainable Development, 19(4), pp. 223-234, 2011. http://dx.doi.org/10.1002/sd.414

review of the available small-scale appropriate technologies for removing arsenic from drinking water. The results provide a guide to the use of appropriate technologies in Pakistan and recommendations are made for both further research and implementation.

\section{Background}

About 65.1\% of Pakistan's 158 million people live in villages (UNFPA, 2005). Houses are usually small clusters of homesteads along small alleys and typically relatives live next to each other and share most of their resources, like the tube wells or hand pumps used for obtaining water. Some village houses have hand pumps inside while others travel to collect water from a nearby well. Water connections are also drawn from a tube well to the house in some villages, where there is electricity to pump the water. The houses are made of mud with thatched roofs and are extended to include sheds for the livestock (chickens, goats, buffaloes and cows). Women and men both work in the fields and are usually employed or in bonded labor by a land lord. Subsistence farming is also practiced. The income of those living in the rural areas of Pakistan is significantly below the Pakistani average. For example, an economic survey encompassing 6 villages in the Gujar Khan Tehsil, one of the seven Tehsils (sub-divisions) in Rawalpindi found that the average annual income per person in such a rural district in Pakistan is about US\$51 (Tahir, 2004) compared to GDP per capita income of U.S. $\$ 720$ (World Bank, 2006) ${ }^{2}$. The income for those in rural districts usually comes from farming and herding.

Although much attention has been drawn to the severe arsenic contamination problems in Bangladesh (Smith, et al., 2000), Pakistan also has a major arsenic problem. Water quality tests in Northern Punjab found that over 20\% of the people are exposed to arsenic contamination in their drinking water (Ahmad et.al, 2004). Drinking water quality tests in 6 major regions of Northern Punjab (Gujrat, Attock, Rawalpindi, Sargodha, Jehlum and Chakwal) were carried out in 4,315 field samples and found $12 \%$ had an arsenic concentration of 10 parts per billion (ppb) or more and $0.6 \%$ had a concentration of $50 \mathrm{ppb}$ or more (Tahir, 2004). The recommended limit set by the Pakistan Standards Quality Control Authority (PSQCA) for arsenic concentrations in drinking water is at 50 ppb while the limit set by the World Health Organization is $10 \mathrm{ppb}$ (PCRWR, 2007b). In general, the sources of drinking water are not centralized. The common sources of drinking water are from wells, tube wells and ponds. Given the distributed nature of the problem and the lack of capital resources that occur predominantly in the rural districts, small-scale distributed water treatment technology is an appropriate technology. Both the modest nature of initiatives from the Pakistani Government (Luken and Hesp, 2007) combined with very limited resources provided by concerned NGOs creates a need for immediate solutions. Small-scale, affordable distributed water treatment technology is a potential immediate solution, which addresses drinking water contamination problems.

\section{Technical Scope and Taxonomy}

2The GDP per capita income of Pakistan can also be represented as an average U.S. \$2,942, based on purchasing-power-parity (IMF, 2007) 
Published as: Fatima Hashmi and Joshua M. Pearce, "Viability of Small-Scale Arsenic-Contaminated Water Purification Technologies for Sustainable Development in Pakistan", Sustainable Development, 19(4), pp. 223-234, 2011. http://dx.doi.org/10.1002/sd.414

Arsenic-free water is required for drinking and cooking purposes to limit human arsenic intake. The average water requirement for drinking (5 L) and cooking or kitchen purposes $(10 \mathrm{~L})$ amount to approximately 15 liters per person per day (Gleick, 1996). Arsenic-removing technologies must reduce the concentration of arsenic from over $50 \mathrm{ppb}$ to less than $10 \mathrm{ppb}$ as per the World Health Organization standards. The technologies must also be affordable for those living in the villages of rural Punjab. In this study, the performance for each of the most commonly used and tested technologies in the field are determined, both over the lifetime of the components and of the entire devices. The cost per unit of water purified is calculated for each technology and compared to determine the economic feasibility.

Many arsenic-removing technologies have been developed on a small scale for villagers to purify their own water. The technologies can be grouped based upon the physical and chemical processes (or combination of processes) used. The five classes of processes considered here are: i) oxidation/reduction, ii) precipitation/coagulation/sedimentation, iii) adsorption/ion exchange, iv) membranes/filters, and v) distillation.

Oxidation/Reduction: Oxidation is the removal of an electron from a compound and reduction is the addition of an electron. Ground water has a considerable amount of iron, which is readily oxidized from $\mathrm{Fe}^{2+}$ to $\mathrm{Fe}^{3+}$. This principle is used to create reactive sites on the substrates that attract arsenic ions. It normally involves auto attenuation, in which water is left standing for some period of time.

Precipitation/Coagulation/Sedimentation: Precipitation is the formation of a solid in a solution during a chemical reaction. Coagulation is the process in which particles aggregate, with the resulting particles termed flocs. Sedimentation is the process in which particles are separated by settling due to gravity. Here, flocs containing arsenic or arsenic precipitates are allowed to settle, due to the action of gravity, and are then removed physically from the drinking water.

Adsorption and Ion Exchange: Adsorption is the process in which molecules or particles bind to a surface and are held there by chemical or physical forces and ion exchange is a chemical process wherein an electrically-charged molecule (anion or cation) in a solution attaches to a solid particle. Ion exchangers, such as clay, can absorb arsenic ions from contaminated water.

Membrane Technologies and Filtration: Low and high pressure membranes have been developed with pores sizes small enough to remove arsenic. Filtration involves the physical separation of solid particles from water by passing through a filter medium that holds the particles, while allowing the water to pass through. Micro-filtration and ultra-filtration employ low pressure membranes, while nano-filtration and reverse-osmosis use high pressure membranes to filter water.

Distillation: This process uses thermal energy to evaporate water, which then condenses on the roof of the device (a cooler surface) and is collected. The impurities and contaminants such as arsenic are left behind. Stills are known to remove salts, heavy metals, and bacteria.

\section{Available Small-Scale Technologies for Removing Arsenic from Water}

\subsection{Three Stage Systems Employing Iron Filings and Sand}

\section{1a Sono 3-Kolshi Filter}

The Sono 3-Kolshi Filter has three pitchers, each on top of the other, which uses the principles of oxidation, precipitation, adsorption, and filtration to remove arsenic from drinking 
Published as: Fatima Hashmi and Joshua M. Pearce, "Viability of Small-Scale Arsenic-Contaminated Water Purification Technologies for Sustainable Development in Pakistan", Sustainable Development, 19(4), pp. 223-234, 2011. http://dx.doi.org/10.1002/sd.414

water. This device was developed by Abdul Hussam of George Mason University and has been studied extensively (Hurd, 2001; Munir, et al., 2001; RAART, 2001; Hussam, 2007). The top pitcher contains $3 \mathrm{~kg}$ of iron fillings and $2 \mathrm{~kg}$ of sand. The pitcher has perforations at the bottom to allow water to pass through it. The second kolshi, or pitcher contains $2 \mathrm{~kg}$ of fine sand and $1 \mathrm{~kg}$ of wood charcoal with perforations at the bottom as well. The third kolshi collects the filtered water. It costs between U.S. \$35 and U.S. \$40 and the water quality of the filtered water exceeds WHO standards. It can be used for 5 to 6 years, filtering up to 200,000 L of water in its lifetime. This system requires constant maintenance, which entails cleaning (washing or changing) the top sand layers.

\section{1b Three Gagri System}

The Three Gagri System consists of 3 pitchers, each on top of the other, and uses the principles of oxidation, precipitation, adsorption, and filtration. Water is added to the top pitcher, which contains zero-valent iron from nail filings and sand; it then flows into the second pitcher which contains fine sand, and collects in the third pitcher at the bottom. A cloth covering the bottom of the top and middle pitchers serves as a filter (Hurd, 2001). These pitchers can hold from 14 to18 L of water and are made from ceramic, plastic or aluminum.

\subsection{Two Stage Systems with Ferric Chloride}

\section{2a Sono 2-Kolshi Filter}

The Sono 2-Kolshi Filter, also known as the ENPHO Arsenic Removal System, is distributed by the Environment and Public Health Organization (ENPHO) in Nepal. This system has two units, a plastic bucket with a $20 \mathrm{~L}$ capacity and a filtration unit consisting of two pitchers (or kolshis), one on top of the other (Hwang, 2001). The filter requires a $4 \mathrm{~g}$ chemical packet made by ENPHO, which contains ferric chloride, charcoal powder and sodium hypochlorite. This packet is added to the $20 \mathrm{~L}$ of water and stirred for a minute. The primary arsenic removal reactions are:

$$
\begin{gathered}
\mathrm{FeCl}_{3}+3 \mathrm{H}_{2} \mathrm{O} \rightarrow \mathrm{Fe}(\mathrm{OH})_{3}(\mathrm{~s})+3 \mathrm{Cl}-+3 \mathrm{H}+ \\
\mathrm{Fe}(\mathrm{OH})_{3}+\mathrm{H}_{2} \mathrm{AsO}_{-} \rightarrow \mathrm{Fe}-\mathrm{As} \text { Complex }
\end{gathered}
$$

It is left to allow the Fe-As complex to settle by gravity for 30 minutes and then stirred again to ensure all the Fe has reacted for 1 minute. This is done four times and takes up to 2 hours. The mixture is then poured into the filtration unit and filtered water is obtained. The initial cost of the device is U.S. \$7. A year's supply of the required chemicals is U.S. \$9.70. This system is technically-viable, but drawbacks include a lack of social acceptability (Hwang, 2001).

\section{2b Stevens Institute Method}

The Stevens Institute Method uses 2 containers, each with a capacity of 20 L (Hwang, 2001). In the first one, chemicals (ferric chloride) are mixed with the arsenic-contaminated water. The second container is a smaller bucket inside a larger one, where arsenic flocs are removed by sedimentation and filtration. The sand bed fills with flocs and needs to be cleaned out twice a week (Ahmed, 2001).

\subsection{Bucket Treatment Unit}

The Bucket Treatment Unit (BTU) uses coagulation and filtration to remove arsenic. It was developed by DANIDA, a Danish aid agency operating in Bangladesh for arsenic mitigation and 
Published as: Fatima Hashmi and Joshua M. Pearce, "Viability of Small-Scale Arsenic-Contaminated Water Purification Technologies for Sustainable Development in Pakistan", Sustainable Development, 19(4), pp. 223-234, 2011. http://dx.doi.org/10.1002/sd.414

removal. The unit consists of 2 plastic buckets capable of holding 20 liters of water each. To the top bucket, $4 \mathrm{~g}$ of alum and $0.04 \mathrm{~g}$ of powdered potassium permanganate are added. The buckets are then placed one on top of the other. Water is added to the top bucket and is stirred for 25 seconds before being left to stand for 3 hours. A sand filter is placed in the bottom bucket to remove any flocs that form and the treated water is taken from a tap at the base of the bottom bucket (Tahura et al, 2001). The BTU system has a daily capacity of treating $20 \mathrm{~L}$ of water and its initial cost is approximately U.S. \$5.10 (Eriksen-Hammel, 2001).

\subsection{Kanchan Arsenic Filter}

Kanchan Arsenic Filter uses a combination of iron nails and sand in a single stage to remove arsenic from drinking water. The Massachusetts Institute of Technology (MIT) in collaboration with ENPHO and the Rural Water Supply and Sanitation Support Program (RWSSSP) developed the Kanchan Arsenic Filter (KAF) after 6 years of research and experimental study. It consists of a large bucket in which water is poured in from the top and passes through a bed of iron nails and a sand layer and emerges arsenic-free from the spout. A total of 15-20 liters of water can pass through in an hour with an arsenic removal efficiency ranging from 85-95\% (Ngai, 2006). The filter in the KAF bucket needs to be cleaned between once a month to once in 6 months, depending largely on the type of area and the initial water quality. The KAF filter costs approximately U.S. \$20 (Ngai, 2006).

\subsection{Silver-Coated Sand Systems}

\section{5a Clay Pitcher Arsenic Removal Filter}

In the Clay Pitcher Arsenic Removal Filter system silver-coated sand is used to remove bacteria while the cast-iron filings increase the efficiency of arsenic removal an arsenic-removing medium. In the Clay Pitcher Arsenic Removal Filter, one 20 L clay pitcher is placed on top of another, with holes of $1 \mathrm{~mm}$ in diameter drilled at the bottom of the top clay pitcher in the center. Two kilograms of silver-coated sand is placed at the bottom of the top pitcher, on top of which $3 \mathrm{~kg}$ of 'arsenic-removing medium' is placed. A further $3 \mathrm{~kg}$ of cast-iron filings are placed on top of the arsenic-removing medium, topped with $3 \mathrm{~kg}$ of plain sand. Experimentation has shown that the filter can handle arsenic contamination up to a $200 \mathrm{ppb}$ concentration, at a daily capacity of 12 liters. The filter lasted for 5 months (treating 1800L of water) after which it had to be replaced (Tahir, 2004).

\section{5b Gravity Flow Arsenic Removal Filter}

The Gravity Flow Arsenic Removal Filter unit consists of two locally-manufactured plastic pitchers placed one on top of the other. The top pitcher has 2 ceramic cartridges containing silvercoated sand and arsenic-removing media on top of the sand. Water is filtered into the lower pitcher by the flow of gravity. This system works in areas that do not have a consistent flow of water supply. Experimentation has shown that this filter removed arsenic from contaminated water up to 25 days, treating a total of $300 \mathrm{~L}$ of water after which the cartridges had to be changed (Tahir, 2004).

\section{5c Arsenic Removal Cartridge Filter}


Published as: Fatima Hashmi and Joshua M. Pearce, "Viability of Small-Scale Arsenic-Contaminated Water Purification Technologies for Sustainable Development in Pakistan", Sustainable Development, 19(4), pp. 223-234, 2011. http://dx.doi.org/10.1002/sd.414

This device consists of a cylinder with a single ceramic cartridge containing silver-coated sand and an arsenic-removing media. In experiments, the filter lasted 25 days with $270 \mathrm{~L}$ of water treated before the filter needed to be changed (Tahir, 2004).

\subsection{Solar Distillation}

A solar still is a device that utilizes the sun's energy to purify water by means of evaporation and condensation. Solar distillation using a single-effect basin holds promise as a method to bring low-cost, clean and ecologically-responsible water to remote populations. Although simple solar stills are relatively inefficient, recent work has shown that compound parabolic concentrators (CPCs) can be used to direct more light onto the still, increasing the throughput and efficiency of these passive solar devices. A computer program has been developed that uses the properties of materials and the solar energy characteristics of the site to calculate the increase in output of water due to reflectors of different heights. For a reflector 2.5 times the width of the still, the output per unit area per day roughly triples while increasing the cost only $10 \%$ and requiring only moderate maintenance (weekly tilts), indicating that CPCs have a significant economic advantage in producing solar distilled water (Pearce and Denkenberger, 2006). Fiberglass Mexican-type stills cost approximately $\$ 100 / \mathrm{m}^{2}$ installed (Yates and Woto, 1998) and inexpensive reflectors cost approximately $\$ 4 / \mathrm{m}^{2}$. For reflectors that are $2.5 \mathrm{X}$ as tall as the width of the still and for a long row of stills which makes the reflector overhang a small fraction of the total, this yields a $10 \%$ increase in cost due to the reflectors. This more than doubles the output so that a single square meter can produce enough water for a person per day in most weather conditions.

\subsection{Promising Experimental Methods of Arsenic Removal}

\section{7a Arsenic Removal Using Bottom Ash (ARUBA)}

Arsenic Removal Using Bottom Ash (ARUBA) is a way of removing arsenic from water, using bottom coal ash that can be recovered very cheaply from coal-fired power plants as a waste material (Berkeley Arsenic Alleviation Group[BAAG], 2007a). These particles are coated with ferric hydroxide, which is then used to remove arsenic for contaminated water (BAAG, 2007b). Ferric hydroxide binds to arsenic, forming $\mathrm{FeAsO}_{4}$ (BAAG, 2007a), which is insoluble in water and can be filtered out. Experiments carried out in the Berkeley Lab have reduced arsenic concentrations from 500 to $10 \mathrm{ppb}$ in 100 liters of water, using 30 grams of arsenic-removing media (BAAG , 2007b). ARUBA has been tested on drinking water in Bangladesh where arsenic was reduced from 500-600 ppb to below $50 \mathrm{ppb}$, and in some villages levels were reduced to below $10 \mathrm{ppb}$. Overall, $0.7 \mathrm{mg}$ of arsenic is removed per gram of treated bottom ash (BAAG, 2007a).

The cost of this arsenic-removing media amounts to U.S. \$1 per kg (BAAG, 2007b), with the estimated cost of raw materials needed for arsenic removal using this system at U.S. \$0.22 per person per year. This device is still under development and testing in the field. Including all other costs, such as transportation of the device, the goal of the Berkley group is to bring the total cost down to $\$ 10$ per person per year by developing it on a community scale. This will require villagers to buy clean water from a central source, rather than having a device in their own house. Large-scale tests of this technology are necessary and are planned for Bangladesh.

\section{7b Nano-removal of Arsenic Contaminated Water}


Published as: Fatima Hashmi and Joshua M. Pearce, "Viability of Small-Scale Arsenic-Contaminated Water Purification Technologies for Sustainable Development in Pakistan", Sustainable Development, 19(4), pp. 223-234, 2011. http://dx.doi.org/10.1002/sd.414

The Centre for Biological and Environmental Nanotechnology (CBEN) at Rice University has developed a technology that can remove arsenic from drinking water using the magnetic properties of nano iron particles known as 'nanorust'(Yavus, et al, 2006). It is well established that arsenic has an affinity for iron particles. When these nanorust particles are added to arseniccontaminated water, arsenic particles gravitate and attach to the nanorust particles, which can then be removed with a very low magnetic field. This has the potential to be an inexpensive solution because the technology can function with a simple hand-held magnet, if the nanorust particles can be developed inexpensively. Currently, nanorust is expensive to produce, but work is in progress on a process of developing this arsenic-removing technology by using materials that are local to arsenicaffected communities in the developing world, thus bringing down the manufacturing cost to an affordable level. Primary raw materials are rust and fatty acids, which can be obtained from olive oil or coconut oil. Field trials have not yet been completed.

\subsection{Systems Failing in the Field}

Not all of the small-scale arsenic-removal systems were shown to be effective in the field, even if in theory and in the laboratory testing the systems were successful at removing the required amount of arsenic. Two such systems are included here for completeness.

\section{8a Jerry Can System}

The Jerry Can System uses adsorption, precipitation and sedimentation to remove arsenic from water (Hurd, 2001). The system consists of a single can or jug, with a capacity of $10 \mathrm{~L}$ and was developed at the University of Colorado, Denver. Water comes in direct contact with the iron fillings while the jug is shaken for 45 minutes or is left to stand for 3 hours. Precipitates of iron and arsenic compounds can then be removed. This U.S. \$0.50 jug can be used 100 times before it has to be replaced and the iron filings changed. The filings cost U.S. \$7/ ton. Although very economic, this system was not successful in its field tests and failed to remove sufficient arsenic from the water. Later it was noted that, in addition to the iron filings, sulfate needed to be added in a relatively complex process to reproduce the laboratory results (Hurd, 2001).

\section{8b Arsenic Removing Unit}

Jalil and Ahmed (2001) developed an Arsenic Removing Unit using oxidation and sedimentation. It is made up of a large tripod stand about $160 \mathrm{~cm}$ long with a plastic bowl on top into which water is poured. This unit is called the oxidation sedimentation unit. A tap at the bottom of the bowl allows the water to flow into another plastic bucket beneath the plastic bowl, making up the filtration unit. Water flows out of this filtration unit into the third and final unit which is the activated alumina adsorption unit. This unit consists of a long, cylindrical plastic pipe through which the treated water passes. In studies of this unit it was concluded that while this system did remove arsenic below 50ppb it was hard for many villagers to maintain and operate (Jalil and Ahmed, 2001).

\subsection{Alternative Solutions}

There are several other processes for remediation of arsenic in drinking water that were not considered here as appropriate technologies. Dilution is an effective method of reaching WHO guidelines (e.g. during the rainy season) and although arsenic concentration levels do drop, this is 
Published as: Fatima Hashmi and Joshua M. Pearce, "Viability of Small-Scale Arsenic-Contaminated Water Purification Technologies for Sustainable Development in Pakistan", Sustainable Development, 19(4), pp. 223-234, 2011. http://dx.doi.org/10.1002/sd.414

not a reliable method for meeting concentration targets. Similarly, arsenic concentration levels are lower in water extracted from deeper wells in Pakistan (Ul-Haque, et al., 2007), but this is a technological solution that would entail constant monitoring and highly differential costs. In biological remediation systems, microorganisms or plants are used to remove toxic compounds. Recently in Pakistan, the plant pterisvitatta (brake fern) was found to effectively remove arsenic from contaminated water. This is a form of 'phytoremediation' process for arsenic removal, involving hyperaccumulation, in which the plant has a large appetite for accumulating arsenic (Naeem, 2005). This system was also not considered because of the difficulty of implementation and the necessary continual testing.

Recently, it has been suggested that chronic low-level arsenicosis might in fact be an arsenicinduced selenium deficiency caused by the formation and excretion of the selenobis (Sglutathionyl)arsinium ion, and thus, selenium supplements have been suggested as a treatment (Gailer et al., 2000). Further work has also suggested that because lentils grown in Saskatchewan, Canada are a naturally-rich source of organic selenium and that selenium has an antagonistic effect on the toxicity of arsenic, it is possible that Se-rich lentils could be a whole-food solution to the arsenicosis in Bangladesh and presumably Pakistan as well (Thavarajah, et al., 2007). These concepts may turn out to be an acceptable whole-food solution to the problem, but far more research is needed on this technique before mass application. The added embodied energy, cost, and the depressing effect on Pakistani agriculture of shipping 'antidote' food from Canada also needs to be further studied.

\section{Results and Discussion}

The economic costs and carrying capacity of the appropriate technologies for arsenic removal from contaminated water reviewed have been summarized in Table 1 . In the second column the carrying capacity of the system is listed so that an estimate of the number of systems for a family of any size can be estimated. In many cases the volume is limited by the size of the buckets, jars, or holding containers, as opposed to by the technology itself. Most of the system performance would not be altered by increasing the size of the volume of held water, with the exception of the solar still. In this case, the less water held in the reservoir, the faster the distillation process. The costs for all the systems were normalized to a daily capacity of $40 \mathrm{~L} /$ day. For some systems, several devices would be necessary to provide 40L/day. Next the initial costs, cost of consumables, lifetime of consumables, and the expected lifetime of the device are listed in columns 3, 4, 5, and 6, respectively. From columns 4 and 5, the operating cost, column 7, of the device is calculated assuming that there is no labor cost. Then in column 8 the total cost of the appropriate technology is calculated by multiplying the lifetime by the operating cost and combining it with the initial cost. Next, the water produced over the lifetime was determined by multiplying the 40L/day by the lifetime in days and is shown in column 9. The different appropriate technology systems produced between 43,000 L and 146,000 L. Finally, the cost from column 8 was divided by the total water produced in column 9 and a the cost of water in US cents/L is shown in column 10 . This is the figure of merit for comparing low cost appropriate technologies over their lifetime, assuming that the device is functioning to meet WHO specifications for safe levels of arsenic. 
Published as: Fatima Hashmi and Joshua M. Pearce, "Viability of Small-Scale Arsenic-Contaminated Water Purification Technologies for Sustainable Development in Pakistan", Sustainable Development, 19(4), pp. 223-234, 2011. http://dx.doi.org/10.1002/sd.414

As can be seen in Table 1, the costs ranged by more than a factor of 50 between 0.035 cents/L for the Stevens Institute Method and over 2 cents/L for the Gravity Flow Arsenic Removal Filter. The devices can be roughly grouped into four categories of cost: low, medium, high, and very high. The very high cost options besides the Gravity Flow system also included the Arsenic Removal Cartridge Filter at 1 cent/L, which would cost a family of four over $\$ 200 /$ year. This is prohibitively expensive for most families in Pakistan, particularly those in rural regions. Those in the high cost category, included the Clay Pitcher Arsenic Removal Filter and the various Solar Stills ranging in cost between 0.18 cents/L and 0.63 cents/L. These devices may be appropriate in some locations, but it is clear how important the longevity of the device is as it plays an enormous role in the life cycle cost of the device. This can be most easily seen by comparing the long, medium and short lifetimes for the CPC-enhanced solar stills, whose costs per liter ranged from 0.2 to 0.6 cents. It is important when deploying appropriate technologies that the materials they are constructed from have the requisite lifetimes to justify the initial costs. Considerably more work is necessary in the field to better quantify lifetimes. Next, the technologies based on Kolshi/Gajiri systems ranged in price from 0.09 to 0.12 cents per $\mathrm{L}$ and were found to be appropriate for many locations. Finally, the least expensive methods of removing arsenic from water are the Stevens Institute Method and Kanchan Arsenic Filter (KAF), which offered costs ranging from 0.03 to 0.05 cents per liter. These methods are both readily applicable to Pakistan. It should be noted that the costs may vary significantly between the technologies in particular regions, even within the same country, because of the availability and price of both the device (e.g. buckets) and consumables (e.g. sand and iron filings). Here for many of the technologies, the majority of the primary cost is in buckets. Plastic buckets are already in common use in these areas of Pakistan, so the initial costs may be negligible for families already able to supply the most expensive materials. In addition, not all of the operating costs were able to be captured. For example, the BTU system needs to be monitored carefully, is only suitable in areas where the concentration of arsenic is 500pbm or more, and the sand needs to be cleaned and boiled every 15 days (Tahura et al, 2001). The cost of the fuel needed to boil the sand was not taken into account here due to the enormous variability in fuel sources and prices.

It is extremely important to note, however, that while cost is a major factor in determining the appropriateness of a technology, it is not the only factor. The two least expensive systems may not be the best choice for a specific location based on several factors including, for example, the capacity of the system needed based on the number of people served. There are also other considerations when choosing a system such as ease of use, social acceptability, smell, cleaning frequency, time for filtration, convenience, and difficulty of handling reagents. For example, the Sono-3-Kolshi has 3 buckets on a stand which is about 5 feet high. It is hard to manage and requires constant maintenance (Tabbal, 2003) and has a low flow rate. The Three Gajri system was found to be effective and appropriate in comparison to the Jerry can system and the Arsenic Treatment Unit in a study done in Nepal (Hurd, 2001) though it has problems with clogging. In Bangladesh, studies of the Three Kolshi systems showed that the filtering process slowed down with an addition of a bucket of water (Khan et al, 2001). The three Gajiri system showed some clogging that increased with increased use, although studies have shown that out of the three bucket (Kolshis) systems, the three Gajiri system proved to be more effective at removing arsenic (Hurd, 2001).

In addition, the experience of the device in the field is also of prime consideration when choosing appropriate technologies. The Sono-2-Kolshi works on the same principle as the Sono-3- 
Published as: Fatima Hashmi and Joshua M. Pearce, "Viability of Small-Scale Arsenic-Contaminated Water Purification Technologies for Sustainable Development in Pakistan", Sustainable Development, 19(4), pp. 223-234, 2011. http://dx.doi.org/10.1002/sd.414

Kolshi but employs 2 buckets instead of 3. A comparison of these technologies with the KAF being used in Nepal showed that the KAF was chosen by the locals as the easiest to operate. Social acceptance of the technologies is hard to determine and despite research on the three technologies in Nepal, because of the complexity of social acceptance, nothing could be concluded on the technologies' acceptability (Tabbal, 2003). The Kanchan Arsenic Filter is also already in use in Bangladesh under the supervision of MIT. Maintenance is not hard and needs to be done every 1 to 6 months when it is observed that the filtration rate is low. The diffuser basin on top is removed and the sand is stirred by hand, then the turbid water is removed and replaced with new water. Once a year, in areas where arsenic is in high concentrations the iron nails are taken out, cleaned, broken and put back in. The Kanchan Arsenic Filter can last for up to 6 years with a fairly high flow rate (Ngai, 2006).

Finally, it should be noted that the assumption that each of the technologies is used properly to effectively reduce the amount of arsenic in water to WHO standards must be considered carefully for deployment of specific technologies outside of the regions in which they were tested, due to the importance of proper use and social acceptability. Programs like the series of On-Farm Water Management Projects in Pakistan would need to be created to properly utilize the critical role of local social actors to ensure the technology is utilized effectively (Cernea, 1993). Further research is needed on the range of technologies in Pakistan to determine the best solution for each locality from both a cost (because of variability in the availability of local materials) and social acceptability viewpoints.

\section{Conclusions and Future Work}

This paper reviewed the available household-scale appropriate technologies for the removal of arsenic in drinking water to assist in just sustainable development in Pakistan. It determined both the technical and economic viability for those that have been deployed in the field in other countries and also reviewed several technologies that are under experimental development. Several technologies were found to be both technically- and economically-viable for Pakistan. The economic viability was based on both first costs and operating costs. The costs for the systems reported in this study represent an averaging for a range of potential uses. The actual costs for the individual or family in Pakistan could in many cases be lower than stated because some of the technologies use local materials families may already own. It was found that even when a technology is cost-effective and made from locally-available materials, issues pertaining to consistent flow rate, maintenance (filter changes), manageability and social acceptance need to be considered as well. This results in the need to identify the locally most appropriate solution. This review article should be helpful for any practitioner in determining the locally optimal solution for the removal of arsenic from drinking water in Pakistan.

\section{References}

Agyeman J, Bullard RD, Evans B. 2003. Just Sustainabilities: Development in an Unequal World, Earthscan/MIT Press: London. 
Published as: Fatima Hashmi and Joshua M. Pearce, "Viability of Small-Scale Arsenic-Contaminated Water Purification Technologies for Sustainable Development in Pakistan", Sustainable Development, 19(4), pp. 223-234, 2011. http://dx.doi.org/10.1002/sd.414

Ahmad T, Kahlown MA, Tahir A, Rashid H. 2001. Arsenic an Emerging Issue: Experiences from Pakistan. Retrieved September 26, 2007, from Loughborough University, Water, Engineering and Development Centre Web site: http://wedc.lboro.ac.uk/conferences/pdfs/30/Ahmad.pdf

Ahmed MF. 2001. An overview of Arsenic Removing technologies in Bangladesh and India. In: M. FerozeAhmed. et al. 2001 (Eds). Technologies for Arsenic Removal from Drinking Water. Bangladesh University of Engineering and Technology: Dhaka, Bangladesh and the United Nations University: Tokyo.

Bennett B, Dudas MJ. 2003. Release of arsenic and molybdenum by reductive dissolution of iron oxides in a soil with enriched levels of native arsenic. J. Environ. Eng. Sci. 2, 265-272.

Berkeley Arsenic Alleviation Group (BAAG). 2007a. Submission to the Bears Breaking Boundaries Competition: Global Poverty Reduction April 23 ${ }^{\text {rd }}, 2007$. Retrieved on October $10^{\text {th }}$, 2007, from University of California Berkeley Website: http://bigideas2.berkeley.edu/BBB\%202007/Mathieu \%20et\%20al_Arsenic_GlobalPoverty.pdf

Berkeley Arsenic Alleviation Group (BAAG). 2007b. Cost Effective Method for Removing Arsenic from Water.Available Technologies. Retrieved on October $\mathbf{2}^{\text {th }}$, 2007, from Berkeley Lab Web site: http://www.lbl.gov:80/Tech-Transfer/techs/lbnl1742.html

Cafer T, Yavuz JT, Mayo W, Yu W, Prakash A, Falkner JC, Yean S, Cong L, Shipley HJ, Kan A, Tomson M, Natelson D, Colvin VL. 2006. Low-Field Magnetic Separation of Monodisperse Fe3O4 Nanocrystals, Science 314(5801): 964-967.

Campos V. 2002. Arsenic in groundwater affected by phosphate fertilizers at Sao Paulo, Brazil. Environ. Geol. 42, 83-87.

Cernea, M. M. 1993. Culture and organization: The social sustainability of induced development. Sustainable Development 1(2), 18-29.

Davenport JR, Peryea FJ. 1991. Phosphate fertilizers influence leaching of lead and arsenic in a soil contaminated with lead arsenate. Water Air Soil Poll. 57- 58: 101-110.

Eriksen-Hamel N, Zinia BKN. 2001. A study of arsenic treatment technologies and teaching the characteristics of arsenic contaminated sludge, In: M. Feroze Ahmed. et al. 2001 (Eds). Technologies for Arsenic Removal from Drinking Water. Bangladesh University of Engineering and Technology:Dhaka, Bangladesh and the United Nations University: Tokyo.

Food and Agriculture Organization (FAO) of the United Nations. 2004. Fertilizer use by crop in Pakistan, FAO: Rome. 
Published as: Fatima Hashmi and Joshua M. Pearce, "Viability of Small-Scale Arsenic-Contaminated Water Purification Technologies for Sustainable Development in Pakistan", Sustainable Development, 19(4), pp. 223-234, 2011. http://dx.doi.org/10.1002/sd.414

Gailer J, George GN, Pickering IJ, Prince RC, Ringwald SC, Pemberton JE, Glass RS, Younis HS, DeYoung DW, Aposhian HV. 2000. A Metabolic Link Between Arsenite and Selenite: The Selenobis(S-glutathionyl) Arsinium Ion. J. Am. Chemical. Society, 122: 4637-4639.

Gleick P. 1996. Basic Water Requirements for Human Activities: Meeting Basic Needs. Water International, 21: 83-92.

Gomez-Caminero A. Howe P. Hughes M. Kenyon, E. Lewis D.R. Moore M., Ng J. Aitio A. Becking, G. 2001. Arsenic and Arsenic Compounds. WHO Environmental Health Criteria No.224.

Grant Thornton International. 2007. Mexico, Indonesia, Pakistan and Turkey-the emerging markets to watch-press release. Retrieved on April 12 ${ }^{\text {th }}, 2008$, from Grant Thornton Website http://www.internationalbusinessreport.com/Press-room/2007/emerging-markets-to-watch.asp

Hurd J.J. 2001. Evaluation of three arsenic removal technologies in Nepal. Masters of Engineering thesis. Massachusetts Institute of Technology: Cambridge, Massachusetts.

Hussam A. Munir A. 2007. A simple and effective arsenic filter based on composite iron matrix: Development and deployment studies for groundwater of Bangladesh. Journal of Environmental Science and Health. Part A 42:1869-1878.

Hwang K.S. 2001. Point of use of arsenic removal from drinking water in Nepal using coagulation and filtration. Thesis, Massachusetts Institute of Technology: Cambridge, Massachusetts.

International Monetary Fund (IMF). 2007. World Economic and Financial Surveys, World Economic Outlook Database, October 2007 Edition, Report for Selected Countries and Subjects: Pakistan, PPP per GDP.

Jacobs M. 1999. Sustainable Development as a Contested Concept. in Dobson A. Fairness and Futurity: Essays on Environmental Sustainability and Social Justice. Oxford University Press: Oxford, UK, 32.

Jalil M.A. Ahmed, F. 2001. Development of an activated alumina based household arsenic removal unit. In: M. FerozeAhmed. et al. 2001 (Eds). Technologies for Arsenic Removal from Drinking Water. Bangladesh University of Engineering and Technology: Dhaka, Bangladesh and the United Nations University: Tokyo.

Khan A.H. Rasul S.B. Munir A.K.M. Habibuddowla M. Akauddin M. Newaz S.S. Hussan A. 2000. Appraisal of a simple arsenic removal method for groundwater of Bangladesh. Journal of Environment Science Health A35(7):1021-1041. 
Published as: Fatima Hashmi and Joshua M. Pearce, "Viability of Small-Scale Arsenic-Contaminated Water Purification Technologies for Sustainable Development in Pakistan", Sustainable Development, 19(4), pp. 223-234, 2011. http://dx.doi.org/10.1002/sd.414

Khan A.H. Rasul S.B. Munir A.K.M. Habibuddowla M. Akauddin M. Newaz S.S. Hussan A. 2001. Evaluation of performance of Sono 3-kolshi filter for arsenic removal from groundwater using zero valent iron through laboratory and field studies. In: M. Feroze Ahmed. et al. 2001 (Eds).

Technologies for Arsenic Removal from Drinking Water. Bangladesh University of Engineering and Technology: Dhaka, Bangladesh and the United Nations University: Tokyo.

Khouri N. Chowdhury S. 1999. Mitigating Natural Groundwater Contamination in Bangladesh: Early Policy Lessons From a Development Project” in Salman, S.MA (ed) Groundwater: Legal and Policy Perspectives. Proceedings of a World Bank Seminar, World Bank Technical Paper No. 456. The World Bank: Washington D.C.

Kim M. J. Nriagu J.O. Haack S. K. 2000. Carbonate ions and arsenic dissolution by groundwater. Environmental Science \& Technology 34: 3094-3100.

Liu J. Zheng H. Aposhian Y. Zhou M. Chen A. Waalkes M. 2002. Chronic arsenic poisonng from burning high-arsenic-containing coal in Guizhou, China. Environmental Health Perspectives 110:119-122.

Luken, R.A. Hesp, P. 2007. The contribution of six developing countries' industry to sustainable development. Sustainable Development 15(4), 242-253.

Masud K. Jaffar M. 1997. Selected trace-metal levels in local vegetables procured from Punjab, Pakistan. Journal of the Chemical Society of Pakistan 19:49-53.

Munir A.K.M. Rasul S. B. Habibuddowla M. Alauddin M. Hussam A. Khan A. H. 2001. Evaluation of the Performance of the SONO3-Kolshi Filter for Arsenic Removal from Groundwater Using Zero Valent Iron Through Laboratory and Field Studies. Proceedings International Workshop on Technology for Arsenic Removal from Drinking Water, Bangladesh University of Engineering and Technology and United Nations University, Japan, May 5, pp. 171-189.

Nahid S. 2001. Arsenic Removal Processes on Trial in Bangladesh. In: M. FerozeAhmed. et al. 2001 (Eds). Technologies for Arsenic Removal from Drinking Water. Bangladesh University of Engineering and Technology:Dhaka, Bangladesh and the United Nations University: Tokyo.

Ngai T. Dangol B. Murcott S. Shrestha R.R. 2006. Kanchan Arsenic Filter. Massachusetts Institute of Technology (MIT) and Environment and Public Health Organization (ENPHO): Kathmandu, Nepal.

Nickson R.T. McArthur J.M. Shrestha B. Kyaw-Myint T.O. Lowry D. 2005. Arsenic and other drinking water quality issues, Muzzaffargarh District, Pakistan. Applied Geochemistry, 20(1):55-68. 
Published as: Fatima Hashmi and Joshua M. Pearce, "Viability of Small-Scale Arsenic-Contaminated Water Purification Technologies for Sustainable Development in Pakistan", Sustainable Development, 19(4), pp. 223-234, 2011. http://dx.doi.org/10.1002/sd.414

Pakistan Council of Research in Water Resource, 2007a. Arsenic Contamination in Ground Water. Retrieved September 7, 2007 from http://www.pcrwr.gov.pk/Arsenic_CP.htm

Pakistan Council of Research in Water Resources (PCRWR). 2007b. Arsenic Contamination in Groundwater of Southern Punjab. Retrieved September 30, 2007, from:

http://www.pcrwr.gov.pk/Arsenic_SP/ASP_TOC.htm

Pearce J.M. Denkenberger D.C.. 2006. Numerical Simulation of the Direct Application of Compound Parabolic Concentrators to a Single Effect Basin Solar Still. Proceedings of the 2006 International Conference of Solar Cooking and Food Processing. 118.

Rapid Assessment of Arsenic Removal Technologies, Phase 1. 2001. Final Draft Report, BAMWSP/DFID/Water Aid.

Sarkar S. Gupta A. Biswas R.K. Deb A.K. Greenleaf J.E. SenGupta, A.K. 2005.Well-head arsenic removal units in remote villages of Indian subcontinent: Field results and performance evaluation. Water Research 39: 2196-2206.

Siegel M. McConnell P. Ilges A. Chen H. Ghassemi A. Thompson R. 2006. Development and evaluation of innovative arsenic adsorption technologies for drinking water by the arsenic water technology partnership. Proceedings NGWA Naturally Occurring Contaminants Conference, Feb 67, 2006, Albuquerque, NM.

Smith A. Lingas E. Rahman M. 2000. Contamination of drinking water by arsenic in Bangladesh: a Public Health Emergency, Bulletin of the World Health Organization 78(9):1093-1103.

Sutherland D. Kabir Md.O., \& Chowdhury, N.A. 2001. Rapid Assessment of Technologies for Arsenic Removal at the Household Level. In: M. Feroze Ahmed. et al. 2001 (Eds). Technologies for Arsenic Removal from Drinking Water. Bangladesh University of Engineering and Technology: Dhaka, Bangladesh and the United Nations University: Tokyo.

Tabbal G. 2003. Technical and social evaluation of 3 arsenic removal technologies in Nepal. Masters of Engineering Thesis. Massachusetts Institute of Technology: Cambridge, Massachusetts.

Tahir M.A. 2004. Assessment of Arsenic and other health significant water quality parameters in groundwater of Northern Punjab. Ph.D. Thesis. Department of Chemistry Bahuddin Zakariya University:Multan, Pakistan.

Tahura S. Shaidullah S.M. RahmanT. Milton A.H. 2001. Evaluation of an Arsenic Removal Household Device: Bucket Treatment Unit (BTU), In: M. Feroze Ahmed. et al. 2001 (Eds). Technologies for Arsenic Removal from Drinking Water. Bangladesh University of Engineering and Technology: Dhaka, Bangladesh and the United Nations University: Tokyo. 
Published as: Fatima Hashmi and Joshua M. Pearce, "Viability of Small-Scale Arsenic-Contaminated Water Purification Technologies for Sustainable Development in Pakistan”, Sustainable Development, 19(4), pp. 223-234, 2011. http://dx.doi.org/10.1002/sd.414

Thavarajah D, Vandenberg A,George GN, Pickering IJ. 2007. Chemical Form of Selenium in Naturally Selenium-Rich Lentils (Lens culinaris L.) from Saskatchewan,, J. Agric. Food Chem. 55 (18):7337 -7341.

Ul-Haque M. Baig D. Nabi W. Hayat. 2007. Groundwater arsenic contamination -- a multidirectional emerging threat to water scarce areas of Pakistan. GQ07: Securing Groundwater quality in urban and industrial environments proceedings. $6^{\text {th }}$ International Water Conference, Fremantle, Australia, 2 - 7 December 2007.

UNFPA. 2005. Country Profiles for Population and Reproductive Health, Policy Developments and Indicators 2005. United Nations Population Fund. Retrieved September18th 2008 from UNFPA Website, http://www.unfpa.org/worldwide/indicator.do?filter=getIndicatorValues

WHO. 2001. Arsenic in Drinking Water- Fact sheet No. 210. Retrieved from WHO Website, http://www.who.int/water_sanitation_health/diseases/arsenicosis/en/

World Bank. 2006, Pakistan Country Overview-2006, Retrieved on April 12, 2008 from The World Bank Website

http://www.worldbank.org.pk/WBSITE/EXTERNAL/COUNTRIES/SOUTHASIAEXT/PAKISTAN EXTN/0,,contentMDK:20131431 menuPK:293059 pagePK:141137 piPK:141127 theSitePK:293 052,00.html

World Commission on Environment and Development (WCED).1987. Our Common Future. Oxford University Press: Oxford.

Yates R. Woto T. 1988. Small Scale Desalination for Remote Areas of Botswana. International Development Centre: Ottawa, Canada. 
Published as: Fatima Hashmi and Joshua M. Pearce, "Viability of Small-Scale Arsenic-Contaminated Water Purification Technologies for Sustainable Development in Pakistan”, Sustainable Development, 19(4), pp. 223-234, 2011. http://dx.doi.org/10.1002/sd.414

\section{Tables}

\begin{tabular}{|c|c|c|c|c|c|c|c|c|c|c|}
\hline Appropriate Technology Device & \begin{tabular}{|c|} 
Water \\
Carrying \\
Capacity \\
(Liters) \\
\end{tabular} & $\begin{array}{c}\text { Initial Cost } \\
\text { of Device } \\
\text { (US\$) }\end{array}$ & $\begin{array}{c}\text { Cost of } \\
\text { Consumables } \\
\text { (US\$) } \\
\end{array}$ & \begin{tabular}{|c|}
$\begin{array}{c}\text { Lifetime of } \\
\text { Consumables } \\
\text { (days) }\end{array}$ \\
\end{tabular} & \begin{tabular}{|c|}
$\begin{array}{c}\text { Lifetime } \\
\text { of total } \\
\text { device } \\
\text { (years) }\end{array}$ \\
\end{tabular} & $\begin{array}{c}\text { Operating } \\
\text { cost per } \\
\text { year (US\$) }\end{array}$ & \begin{tabular}{|c} 
Total cost \\
over \\
lifetime \\
(US\$)
\end{tabular} & $\begin{array}{c}\begin{array}{c}\text { Water } \\
\text { produced } \\
\text { over lifetime } \\
\text { (Liters) }\end{array} \\
\end{array}$ & \begin{tabular}{|c|} 
Cost of \\
water (cents/ \\
Liter)
\end{tabular} & References \\
\hline 4.1a Sono 3-Kolshi & 50 & $\$ 35.50$ & $\$ 4.50$ & 140 & 5 & $\$ 11.73$ & $\$ 94.16$ & 73,000 & 0.1290 & Munir et al, 2001 and Hussam, 2007 \\
\hline 4.1 b 3 Gagri System & 4 & $\$ 10.50$ & $\$ 4.50$ & 140 & 5 & $\$ 11.73$ & $\$ 69.16$ & 73,000 & 0.0947 & Hurd, 2001 \\
\hline 4.2a Sono 2-Kolshi Filter & 20 & $\$ 16.70$ & $\$ 9.70$ & 365 & 5 & $\$ 9.70$ & $\$ 65.20$ & 73,000 & 0.0893 & Tabbal, 2003 and Hwang, 2002 \\
\hline 4.2b Stevens Institute Method & 20 & $\$ 9.50$ & $\$ 2.00$ & 365 & 3 & $\$ 2.00$ & $\$ 15.50$ & 43,800 & 0.0354 & Hwang, 2002 \\
\hline 4.3 Bucket treatment Unit (BTU) & 20 & $\$ 6.50$ & NA & NA & 3 & NA & $\mathrm{NA}$ & 43,800 & NA & Eriksen-Hamel, 2001 \\
\hline 4.5a Clay Pitcher Arsenic Removal Filter & 12 & $\$ 14.15$ & $\$ 9.98$ & 150 & 5 & $\$ 24.28$ & $\$ 135.57$ & 73,000 & 0.1857 & Tahir, 2004 \\
\hline 4.5b Gravity Flow Arsenic Removal Filter & 12 & $\$ 28.75$ & $\$ 20.00$ & 25 & 5 & $\$ 292.00$ & $\$ 1,488.75$ & 73,000 & 2.0394 & Tahir, 2004 \\
\hline 4.5c Arsenic Removal Cartridge Filter & 10.8 & $\$ 26.67$ & $\$ 10.00$ & 25 & 5 & $\$ 146.00$ & $\$ 756.67$ & 73,000 & 1.0365 & Tahir, 2004 \\
\hline 4.6 Solar Still + CPC (1 m2) long life & 50 & $\$ 277.68$ & $\$ 0.00$ & NA & 10 & $\$ 0.00$ & $\$ 277.68$ & 146,000 & 0.1902 & Pearce and Denkenberger, 2006 \\
\hline 4.6 Solar Still + CPC ( $1 \mathrm{~m} 2)$ medium life & 50 & $\$ 277.68$ & $\$ 0.00$ & NA & 5 & $\$ 0.00$ & $\$ 277.68$ & 73,000 & 0.3804 & Pearce and Denken berger, 2006 \\
\hline 4.6 Solar Still + CPC (1 m2) short life & 50 & $\$ 277.68$ & $\$ 0.00$ & $\mathrm{NA}$ & 3 & $\$ 0.00$ & $\$ 277.68$ & 43,800 & 0.6340 & Pearee and Denkenberger, 2006 \\
\hline 4.7 ARUBA & - & 0 & 1.76 & 365 & 1 & $\$ 80.00$ & $\$ 80.00$ & 73,000 & 0.1096 & BAAG, 2007b \\
\hline 4.8a Jerry Can System & 50 & 0.5 & $\$ 4.50$ & 25 & 5 & $\$ 65.70$ & $\$ 329.00$ & 73,000 & 0.4507 & Hurd, 2001 \\
\hline
\end{tabular}

Table 1. Comparison of capacity and costs of appropriate technologies to remove arsenic from drinking water in Pakistan. 